\title{
Balanced Coagonist of GLP-1 and Glucagon Receptors Corrects Dyslipidemia by Improving FGF21 Sensitivity in Hamster Model
}

\author{
Authors

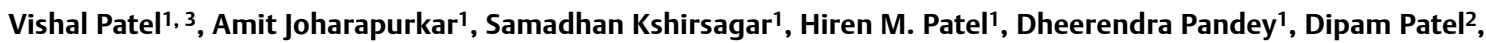 \\ Brijesh Sutariya', Maulik Patel1, Rajesh Bahekar², Mukul R. Jain'1
}

\section{Affiliations}

1 Department of Pharmacology \& Toxicology, Zydus Research Centre, Cadila Healthcare Limited, Moraiya, Ahmedabad, India

2 Department of Medicinal Chemistry, Zydus Research Centre, Cadila Healthcare Limited, Moraiya, Ahmedabad, India

3 K.B. Institute of Pharmaceutical Education and Research, Gandhinagar, Gujarat, India

Key words

insulin/glucagons, lipid-lowering drugs, drug research

received $\quad 30.06 .2017$

accepted 18.08.2017

\author{
Bibliography \\ DOI https://doi.org/10.1055/s-0043-118808 \\ Published online: 12.9.2017 \\ Drug Res 2017; 67: 730-736 \\ (c) Georg Thieme Verlag KG Stuttgart · New York \\ ISSN 2194-9379
}

\section{Correspondence}

Amit Joharapurkar

Department of Pharmacology \& Toxicology

Zydus Research Centre

Cadila Healthcare Limited

Sarkhej-Bavla N.H.No.8A

382210, Moraiya, Ahmedabad

India

Tel.: +91/271/7665 555, Fax: +91/271/7665 155

amitjoharapurkar@zyduscadila.com

\begin{abstract}
Hyperlipidemia is often associated with obesity and diabetes, and can lead to serious complications like atherosclerosis and fatty liver disease. Coagonist of GLP-1 and glucagon receptors is a therapy under clinical investigation for treatment of obesity and diabetes. In this study, we have characterized the mechanism of hypolipidemic effect of a balanced coagonist using high cholesterol-fed hamsters. Tyloxapol-induced hypertriglyceridemia, lipolysis in adipose tissue, and bile homeostasis were assessed after repeated dose treatment of the coagonist of GLP-1 and glucagon receptors (Aib2 C24 chimera 2, SC). Antagonists of GLP-1, glucagon, and FGF21 receptors were coadministered, and FGF21 sensitivity was determined in liver and adipose tissue. Repeated dose treatment of coagonist reduced cholesterol and increased FGF21 in blood and liver. Coagonist treatment reduced hepatic triglyceride secretion, increased lipolysis and reduced body weight. Antagonism of GLP-1 and glucagon receptors partially blocked the effect of the coagonist on lipid metabolism in circulation and liver, while FGF21 receptor antagonist completely abolished it. Glucagon and GLP-1 receptors antagonists blocked the action of coagonist on cholesterol excretion and bile flow in liver, but FGF21 antagonist was not effective. Treatment with the coagonist increased expression of FGF21, FGF21R and cofactor BKlotho in liver and adipose. In conclusion, coagonist of GLP-1 and glucagon receptors improved lipid metabolism in liver of dyslipidemic hamsters. This effect is partially mediated by GLP-1 and glucagon receptors, and the improved FGF21 sensitivity could be the mechanism of hypolipidemic action of the coagonist of GLP-1/glucagon receptors.
\end{abstract}

\section{Introduction}

Dyslipidemia is a conventional risk factor for atherosclerosis and cardiovascular morbidity and mortality, characterized by abnormally high levels of triglycerides, cholesterol, and low-density lipoprotein (LDL) levels [1, 2]. Agonizing glucagon-like peptide 1 (GLP1) receptor (GLP-1R) and glucagon receptor (GCGR), using a single coagonist, is an emerging therapeutic approach for treatment of diabetes and obesity. GLP-1 and glucagon control distinct pathways in regulating glucose production and disposal. Recent studies have demonstrated that actions of these two hormones can be complimentary in achieving optimum therapeutic effect in obesity and diabetes [3, 4]. GLP-1 improves glucose tolerance, and decreases appetite [5]. On the other hand, glucagon increases gluconeogenesis, thermogenesis, satiety, and reduces body weight. Studies using peptide Aib2 C24 chimera2, a balanced GLP-1R/GCGR coagonist have demonstrated that balancing the opposing effects of GLP-1R and GCGR activation showed improvement in diabetes and obesity in animal models [6]. Oxyntomodulin, a dual agonist of GLP-1R and GCGR, showed appetite suppression, weight loss, and increased energy expenditure in humans [7]. 

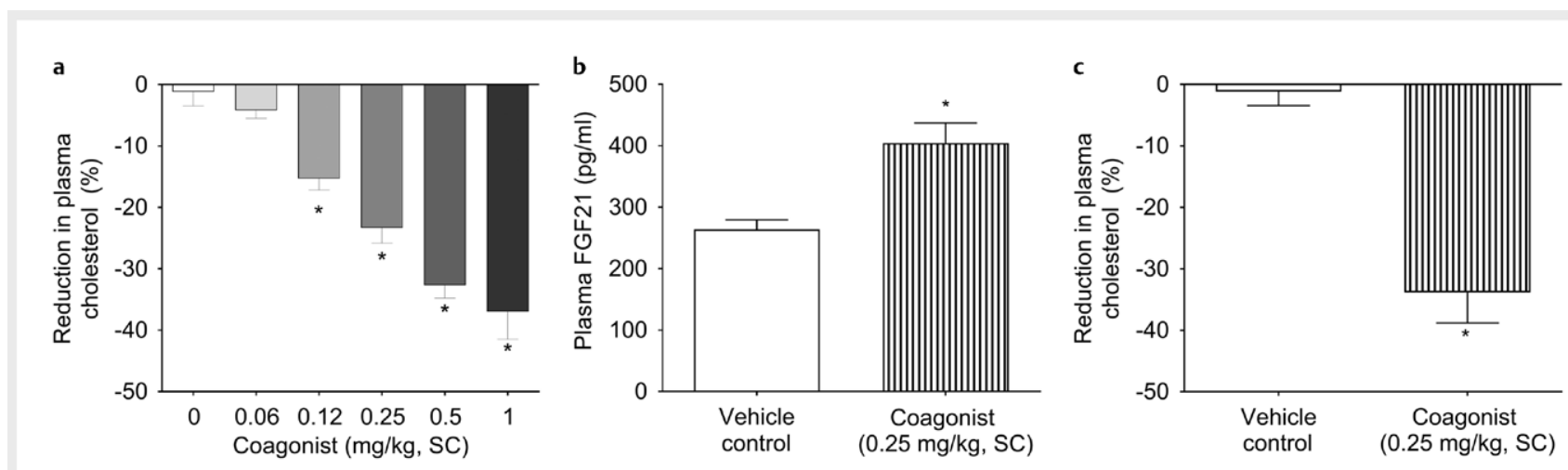

- Fig. 1 Effect of coagonist on a. Reduction in plasma cholesterol (\%) after single dose administration, and effect of repeated dose treatment of coagonist on b. Plasma FGF21 levels, and c. Reduction in plasma cholesterol (\%) in hyperlipidemic hamsters. Data are presented as means \pm SEM $(n=6) .{ }^{*}, P<0.05$, when compared with vehicle control.

It is interesting to note that GLP-1 agonists reduce postprandial dyslipidemia, triglycerides, LDL and total cholesterol [8, 9]. Glucagon regulates lipid synthesis, secretion, and oxidation [10,11]. We have demonstrated that activation of GLP-1R regulates circulating and hepatic lipids by reducing sterol regulatory element-binding transcription factor 1 (SREBP-1c) and increasing LDL receptor (LDLR) and cholesterol 7 alpha-hydroxylase (CYP7A1) [12]. These effects were partially independent of anorexia induced by GLP-1R activation. We have also observed that repeated dose treatment of glucagon (central as well as peripheral) reduces circulating and hepatic lipids, mainly LDL, and enhances cholesterol excretion in bile, by reducing expression of HMG-CoA reductase and increasing that of ATP-binding cassette transporter A1 (ABCA1) [13]. These findings indicate that unlike their opposing effects on glucose metabolism, GLP-1R and GCGR agonists have similar effects on major aspects of lipid metabolism. However, the molecular pathways by which these effects are achieved appear to be distinct. We have previously observed that coagonist treatment improves metabolic profile by actions on GLP- 1 and glucagon receptors, which was associated with improvement in Fibroblast growth factor 21 (FGF21) levels [14]. In studies reported here, we investigated the pharmacological contribution of concurrently agonizing the GLP-1 receptor and GCGR on lipid homeostasis in diet-induced hyperlipidemic male golden Syrian hamsters.

\section{Materials \& Methods}

\section{Chemicals and reagents}

Coagonist of GCGR and GLP-1R, Aib2 C24 chimera 2 ( $\mathrm{H}^{1}$ XQGT5FTSDY ${ }^{10}$ SKYLD $^{15} \mathrm{EQAAK}^{20} \mathrm{EFICW}^{25} \mathrm{LMNT}^{-N_{2}}{ }_{2}$ ), GLP-1R antagonist exendin(9-39), GCGR antagonist (DesHis ${ }^{1}$ DesPhe ${ }^{6}$ glucagon-amide) and FGF21R antagonist ( $\triangle \mathrm{N} 17$ ) were synthesized at Zydus Research Centre using methods reported in literature [6, 15-17]. Plasma FGF21 was measured using a FGF21 ELISA assay (Wuhan Eiaab science, CO.,LTD. China). Triglycerides, total cholesterol, and LDL cholesterol were measured using kits purchased from RCFL (New Delhi, INDIA).

\section{Animals}

Male golden Syrian hamsters (8-10 weeks old) were obtained from the Animal Research Facility of Zydus Research Centre. Animals were allowed free access to chow diet and water and were kept on a 12-h light/dark cycle. The study protocol was reviewed and approved by Institutional Animal Ethics Committee (IAEC) of Zydus Research Centre (Ahmedabad, India), an AAALAC approved facility. Hamsters were fed on high fat high cholesterol diet (HFHC, 44\% kcal fat and $0.5 \%$ cholesterol, D06050501; Research Diets, Inc., New Brunswick, NJ) for 14 days to induce hypercholesterolemia. Then they were grouped based on cholesterol and triglyceride levels and were randomly assigned to a treatment group in separate experiments, as described below for 28 days. The high fat high cholesterol diet was continued throughout the study treatment period. Hamsters selected for each treatment group were $n=12$. After the treatment they were randomized into two sets. One set $(n=6)$ was used for bile homeostasis, lipolysis, gene expression, and plasma biochemistry. Another set of treated hamsters $(n=6)$ was used in triton-induced hypertriglyceridemia studies.

Hypercholesterolemic hamsters were randomized and administered vehicle (deionized water) or $0.25 \mathrm{mg} / \mathrm{kg}$ of co-agonist, subcutaneously (SC) twice daily, at 09:30 and 18:00 h, for 28 days. In addition, hamsters were administered combinations of the coagonist with antagonists of GLP-1R $(0.15 \mathrm{mg} / \mathrm{kg}, \mathrm{SC}), \mathrm{GCGR}(0.3 \mathrm{mg} /$ $\mathrm{kg}, \mathrm{SC})$, and FGF21R $(0.5 \mathrm{mg} / \mathrm{kg}, \mathrm{SC})$, with the same frequency for 28 days. Body weight was recorded daily. This dose of coagonist was based on a pilot study where it showed a dose-related hypolipidemic effect from $0.06 \mathrm{mg} / \mathrm{kg}$ to $1 \mathrm{mg} / \mathrm{kg}$ ( $\triangleright$ Fig. 1a). Doses of the antagonists were decided in separate pilot studies as per previous reports $[15,18,19]$.

On day 29 of treatment, animals were bled $(500 \mu \mathrm{L})$ and plasma was separated for the determination of total cholesterol, triglycerides, LDL cholesterol and FGF21. Animals were sacrificed and tissue samples were collected and stored at $-80^{\circ} \mathrm{C}$ for further analysis. All liver samples were analyzed for lipid content. 


\section{Effect of repeated dose treatment of coagonist on tyloxapol induced hypertriglyceridemia}

Hamsters were anaesthetized using pentobarbital $(45 \mathrm{mg} / \mathrm{kg}, \mathrm{IP})$, jugular vein was cannulated, and the animals were allowed to recover for three days. After overnight fasting, animals were injected tyloxapol (Triton WR-1339, $250 \mathrm{mg} / \mathrm{kg}$, IV). Animals were bled ( $50 \mu \mathrm{L}$ per time point) by retro-orbital puncture under isofluorane anesthesia at $0,0.5,1,1.5$ and $2 \mathrm{~h}$ after tyloxapol treatment. Plasma samples were analyzed for triglyceride content.

\section{Effect of repeated dose treatment of coagonist on bile homeostasis}

Hamsters were anaesthetized with pentobarbital $(45 \mathrm{mg} / \mathrm{kg}, \mathrm{IP})$. An abdominal incision was made and the bile duct was cannulated with PE-10 tubing (Becton Dickinson, Sparks, MD, USA). Body temperature was monitored with a rectal thermometer and maintained at $37^{\circ} \mathrm{C}$ with a thermal blanket. Bile fluid was collected for $15 \mathrm{~min}$. Bile samples were centrifuged to precipitate biliary proteinaceous components and weighed to estimate bile fluid content. Cholesterol content in the bile fluid was estimated.

\section{Determination of hepatic triglycerides}

A sample of liver tissue was homogenized in a heptane-isopropanol-Tween 80 mixture (3:2: 0.01 by volume) and centrifuged at $1500 \mathrm{~g}$ for $15 \mathrm{~min}$ at $4^{\circ} \mathrm{C}$. The supernatant (the upper phase contained extracted triglycerides) was collected and evaporated using a nitrogen evaporator. Residue was reconstituted in triton $\times 100$ : t-butyl alcohol. Triglyceride content was determined using a triglyceride kit [20].

\section{Determination of lipolytic effect in adipocytes}

After bile homeostasis assessment, adipocytes were isolated. Animals were sacrificed by cervical dislocation and epididymal fat was collected in ice cold phosphate-buffered saline (PBS). Approximately $1.5-2 \mathrm{~g}$ of isolated fat pads were suspended in $2.0 \mathrm{~mL}$ disintegration medium (MEM-Eagle containing $5 \mathrm{mM} \mathrm{NaHCO}_{3}, 20 \mathrm{mM}$ HEPES and $10 \%$ bovine serum albumin (BSA), and $\mathrm{pH}$ was adjusted to 7.8 and $2 \mathrm{mg} / \mathrm{ml}$ Collagenase $\mathrm{H}$ added after $\mathrm{pH}$ adjustment) and were dissected into smaller pieces. This mixture was incubated for $30 \mathrm{~min}$ at $37^{\circ} \mathrm{C}$ in a shaking water bath. The resulting suspension was diluted to $20 \mathrm{ml}$ with disintegration medium and filtered through muslin cloth. Cell suspension was washed thrice with culture medium (MEM-Earle containing $5 \mathrm{mM} \mathrm{NaHCO}$, $20 \mathrm{mM} \mathrm{HEPES}$, and $2.5 \% \mathrm{BSA}, \mathrm{pH}-7.4$ ) to remove the collagenase solution by spinning the filtrated suspension down for $30 \mathrm{~s}$ at $40 \times \mathrm{g}$ and discarding the lower phase (adipocytes float as the upper phase). Adipocytes were resuspended in culture medium and approximately $1.56 \times$ $10^{6}$ cells/ml were used in the lipolysis assay. Five hundred microliter of the cell suspension was added to incubator vial, with or without L-noradrenaline $(10 \mu \mathrm{M})$. The mixture was then incubated at $37^{\circ} \mathrm{C}$ for $1 \mathrm{~h}$ with shaking. Reaction was stopped by placing tube in ice for $20 \mathrm{~min}$. These samples were centrifuged (3000 rpm for $10 \mathrm{~min}$ at $4^{\circ} \mathrm{C}$ ) and lower phase was analyzed for glycerol content [21].

\section{Gene expression analysis}

Tissue samples were homogenized in TRIzol reagent (Invitrogen, Life Technologies, Carlsbad, CA, USA) using a Polytron hand-held homogenizer (Kinematica, Bohemia, NY, USA).

Total RNA extracted from the liver samples by TRIzol reagent (Invitrogen Life Technologies, Carlsbad, CA, USA) in accordance with the supplier's instructions. One microgram total RNA from each sample was used for first-strand cDNA synthesis using High Capacity cDNA Archive Kit (Applied Biosystems, Foster City, CA, USA; Part No. 4322171). An equal amount of cDNA from each sample was used for quantitative real-time PCR using ABlprism-7300 (Applied Biosystems, Foster City, CA, USA). Gene expression of FGF21 forward primer (5'-3') GGCACCTCTACACAGACGAC, reverse primer (5'-3') CCAGGATTTGGATGACCCCC, FGF21R forward primer (5'-3') GGAGTTCATGTGTAAGGTGTACAGTGA, reverse primer $\left(5^{\prime}-3^{\prime}\right)$ GTGGTATTAACTCCAGCAGTCTTCAG and ßklotho forward primer $\left(5^{\prime}-3^{\prime}\right)$ CTGATCAAGGCACATTCGAAAG, reverse primer (5'3') TGGGACCCCAAGGTGATG were determined using SYBR Green quantitative real-time PCR and QIAGEN QuantiFast SYBR Green kit. Bactin (5-3' TGTCACCAACTGGGACGATA and 5-3' AACACAGCCTGGATGGCTAC) was used as an internal control for normalization of the results.

\section{Statistical analysis}

Statistical analysis was performed by one-way ANOVA with Dunnett's post-hoc test using the GraphPad Prism version 7.01 for Windows (GraphPad Software Inc., San Diego, California, USA). Results expressed as mean \pm SEM; $p<0.05$ considered as statistically significant.

\section{Results}

\section{Coagonist treatment causes reduction in cholesterol and increased FGF21 secretion}

Coagonist of GLP-1R and GCGR reduced cholesterol in repeated dose treatment, but the mechanism of this effect was not known. We investigated whether FGF21 secretion increased due to chronic treatment of the coagonist. We have found that the coagonist treatment caused an increase in FGF21 concentration in plasma ( $\triangleright$ Fig. 1b), which was accompanied by reduction in cholesterol (• Fig. 1c).

\section{Effect of coagonist on hepatic triglyceride secretion is mediated by FGF21}

To examine the effect of simultaneous activation of GLP-1R and GCGR on secretion of very low density lipoprotein (VLDL)-rich triglycerides in hamsters, we inhibited lipoprotein lipase with tyloxapol $(250 \mathrm{mg} / \mathrm{kg})$ and monitored the rate of triglyceride release in plasma over time. Coagonist administration diminished the tyloxapol-induced rise in plasma triglycerides ( $\mathbf{F i g}$. 2a). To study the role of FGF21 in mediating the effect of the coagonist on hepatic triglyceride secretion, we also administered antagonists of GLP-1R, GCGR, and FGF21R along with the coagonist for 28 days. Treatment of either GLP-1R or GCGR antagonist partially inhibited this decrease, whereas FGF21 antagonist completely abolished this 


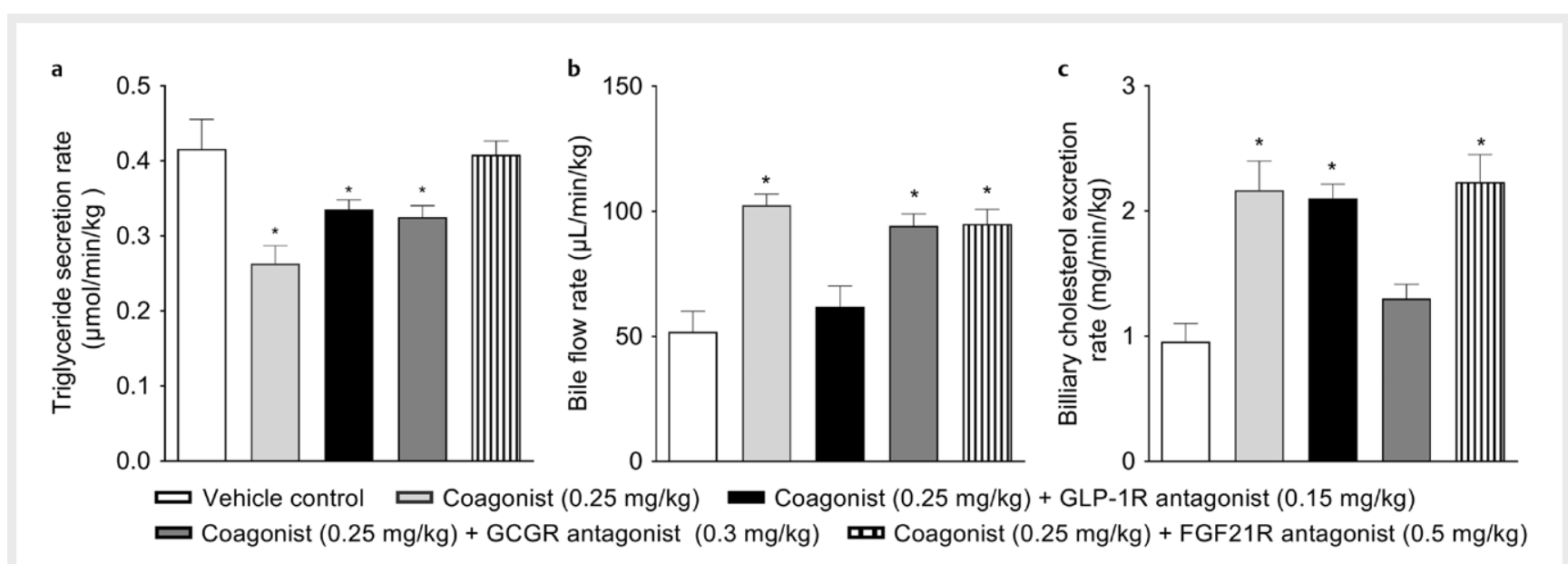

- Fig. 2 Effect of repeated dose treatment of coagonist on a. triglyceride secretion rate, $\mathbf{b}$. bile flow rate and c. cholesterol excretion in bile in hyperlipidemic hamsters. Data are presented as means \pm SEM $(n=6) .{ }^{*}, P<0.05$ when compared with vehicle control.

effect of coagonist ( $\vee$ Fig. 2 a). Taken together with earlier studies on different coagonists, our data suggests that coagonist affects hepatic lipid metabolism by modulation of hepatic triglyceride assembly $[6,14,22]$.

\section{Effect of coagonist on biliary cholesterol excretion is independent of FGF21}

This is the first study which examined the effect of GLP-1R and GCGR coagonist on biliary cholesterol excretion in hyperlipidemic hamsters. Coagonist treatment $(0.25 \mathrm{mg} / \mathrm{kg})$ showed a significant rise in bile flow rate and cholesterol excretion in bile ( $\vee$ Fig. $\mathbf{2 b}, \mathbf{c}$ ). GLP-1R antagonist prevented rise in bile flow rate, but it did not affect cholesterol excretion in bile. Treatment with GCGR antagonist attenuated coagonist-induced biliary excretion of cholesterol ( $>$ Fig. 2c). On the other hand, FGF21R antagonist failed to alter either bile flow rate or biliary cholesterol excretion induced by coagonist ( Fig. 2b,c).

\section{Coagonist treatment regulated lipolysis in adipocytes}

We isolated adipocytes from hamsters treated with coagonist for 28 days. Coagonist treatment led to increase in lipolysis when compared to vehicle-treated animals. Effect of coagonist was partially reversed in presence of GLP-1R antagonist and GCGR antagonist, while in presence of FGF21R antagonist, glycerol release was completely reduced ( $\triangleright$ Table 1 ). We also assayed L-noradrenaline stimulated lipolysis. Coagonist treated hamsters showed significant increase in L-noradrenaline stimulated lipolysis when compared with vehicle control group. Chronic administration of GLP-1R and GCGR antagonist along with coagonist partially reversed lipolytic response of coagonist. Blockade of FGF21R action fully suppressed lipolysis that was stimulated by coagonist treatment ( Table 1).

\section{Effects of the coagonist on body weight and food intake are not dependent on FGF21}

Hamsters fed on high fat- high cholesterol diet were treated either with vehicle or with the coagonist, with or without the antagonists of GCGR, GLP-1R, and FGF21R. The animals treated with vehicle gained $18.2 \mathrm{~g}$ weight in treatment duration. Those hamsters which received coagonist treatment lost $33.4 \mathrm{~g}$, which indicates $33.8 \%$ decrease against the control. Blockade of GCGR induced $9.0 \mathrm{~g}$ weight loss, which was $15.6 \%$ lesser than the coagonist treated group. On the other hand, blocking the GLP-1R induced $5.6 \mathrm{~g}$ weight loss, which was $17.8 \%$ lesser than the coagonist treated group. When FGF21R antagonist was added to the treatment along with coagonist, the hamsters gained $5.7 \mathrm{~g}$, which was $8.2 \%$ lesser than the vehicle treated control ( $\vee$ Table 1 ).

Food intake in coagonist-treated hamsters was significantly decreased when compared to the vehicle treated controls. However, when GCGR antagonist treated was added, the decrease in food intake induced by the coagonist was nearly attenuated. On the other hand, GLP-1R antagonist attenuated the anorexia induced by the coagonist minimally, despite the body weight being significantly lower. Treatment with the FGF21R antagonist did not alter anorexia induced by coagonist ( $\triangleright$ Table 1). Taken together, these data suggest that the effect of coagonist on body weight and food intake are differentially regulated by glucagon and GLP-1 signaling, and are not dependent on FGF21.

\section{FGF21 signalling is required for lipid lowering effect of coagonist}

Repeated treatment of coagonist of GLP-1R and GCGR improved the dyslipidemia induced by high fat and high cholesterol diet in hamsters. The triglyceride in plasma was reduced by $42.6 \%$, whereas the cholesterol reduction was observed to be $53.7 \%$. The reduction in cholesterol was mainly due to reduction in LDL. Hamsters treated additionally with GLP-1R antagonist showed a significant blockade of the coagonist-induced reduction in plasma triglycerides (21.3\% against control), while the effect on plasma cholesterol was minimal. Blockade of GCGR completely reversed the effect of coagonist on cholesterol, with a lesser impact on triglycerides. Blocking FGF21 action completely reversed the hypolipidemic effect of the coagonist ( $\triangleright$ Fig. 3). Cholesterol fed hamsters showed 
- Table 1 Effect of chronic treatment of coagonist on body weight, food intake, hepatic lipids, and glycerol release in hyperlipidemic hamsters.

\begin{tabular}{|c|c|c|c|c|c|}
\hline Parameter & $\begin{array}{l}\text { Vehicle } \\
\text { control }\end{array}$ & $\begin{array}{c}\text { Coagonist of GLP-1R } \\
\text { and GCGR } \\
(0.25 \mathrm{mg} / \mathrm{kg}, \mathrm{SC})\end{array}$ & $\begin{array}{c}\text { Coagonist }+ \text { GLP-1R } \\
\text { antagonist } \\
(0.15 \mathrm{mg} / \mathrm{kg}, \mathrm{SC})\end{array}$ & $\begin{array}{c}\text { Coagonist + GCGR } \\
\text { antagonist } \\
(0.3 \mathrm{mg} / \mathrm{kg}, \mathrm{SC})\end{array}$ & $\begin{array}{c}\text { Coagonist + FGF21R } \\
\text { antagonist } \\
(0.5 \mathrm{mg} / \mathrm{kg}, \mathrm{SC})\end{array}$ \\
\hline Body weight $(\mathrm{g})$ & $152.4 \pm 5.9$ & $100.8 \pm 3.7^{*}$ & $128.6 \pm 5.1^{*}$ & $125.2 \pm 3.8^{*}$ & $139.9 \pm 4.3 \#$ \\
\hline $\begin{array}{l}\text { Total Food intake(g)/ } \\
\text { animal }\end{array}$ & $143.3 \pm 4.3$ & $98.3 \pm 3.2^{*}$ & $121.3 \pm 2.4^{*} \#$ & $135.2 \pm 3.4 \#$ & $102.3 \pm 5.3^{*}$ \\
\hline $\begin{array}{l}\text { Hepatic triglyceride } \\
\text { (mg/g of tissue) }\end{array}$ & $54.7 \pm 2.3$ & $21 \pm 1.1^{*}$ & $43.4 \pm 2.1 * \#$ & $33.3 \pm 2.2^{*} \#$ & $49.4 \pm 2.1 \#$ \\
\hline $\begin{array}{l}\text { Hepatic total cholesterol } \\
\text { (mg/g of liver) }\end{array}$ & $12.9 \pm 0.6$ & $6.6 \pm 0.6^{*}$ & $7.6 \pm 0.5^{*}$ & $10.0 \pm 1.1^{*} \#$ & $7.3 \pm 0.9^{*}$ \\
\hline \% glycerol release (Basal) & $32.4 \pm 1.9$ & $72.1 \pm 5.9^{*}$ & $57.3 \pm 4.6 * \#$ & $48.1 \pm 4.5^{*} \#$ & $37.4 \pm 1.9 \#$ \\
\hline $\begin{array}{l}\text { \% glycerol release } \\
\text { (L-noradrenaline } \\
\text { stimulated) }\end{array}$ & $67.7 \pm 4.5$ & $182.1 \pm 13.4^{*}$ & $132.1 \pm 13.4^{*} \#$ & $92.1 \pm 13.4^{*} \#$ & $53.2 \pm 3.6 \#$ \\
\hline
\end{tabular}

Data are presented as mean \pm SEM ( $n=6$ in each group). ${ }^{*}$ Significant difference between coagonist group and vehicle group $(p<0.05)$, \#Significant difference between coagonist group and antagonist group (Exendin-9, GCGR antagonist and FGF21R antagonist) $(p<0.05)$

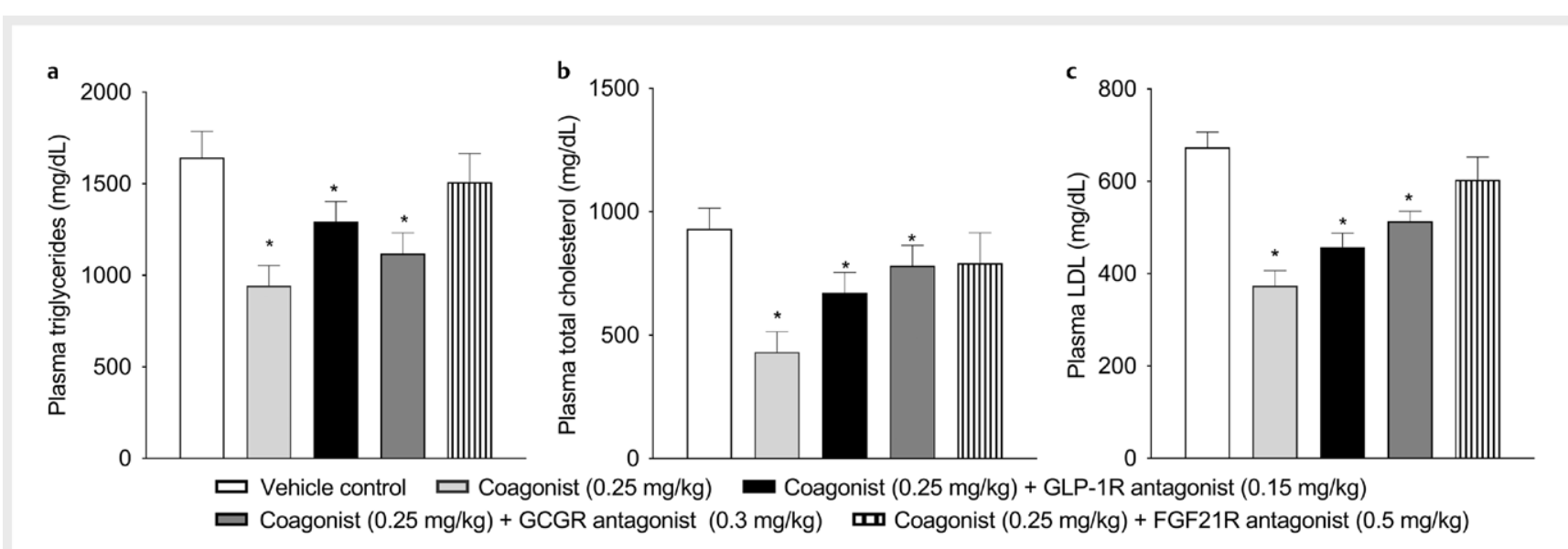

- Fig. 3 Effect of chronic treatment of coagonist on a. plasma triglycerides and b. plasma total cholesterol, and c. plasma LDL in hyperlipidemic hamsters. Data are presented as means $\pm \operatorname{SEM}(n=6) .{ }^{*}, P<0.05$, when compared with vehicle control.

increased accumulation of triglycerides and cholesterol in liver. Coagonist treatment significantly reduced hepatic triglycerides and total cholesterol ( $\vee$ Table 1). Coadministration GLP-1R and FGF21R antagonists prevented the effect of coagonist on hepatic triglycerides, while GCGR blockade prevented coagonist-induced reduction in hepatic cholesterol ( $\triangleright$ Table 1).

To confirm the involvement of FGF21 in metabolic actions of coagonist we assessed mRNA expression of FGF21, FGF21R and ßklotho in vehicle control and coagonist treated animals. We observed that chronic treatment of coagonist increased mRNA expression of FGF21 and FGF21R in liver, and adipose. An increase in Bklotho expression indicates increased FGF21 sensitivity after coagonist treatment ( $\triangleright$ Fig. 4). The changes in FGF21 sensitivity strongly correlates with beneficial effect on lipid, indicating a role of adipose and hepatic FGF21 axis in modulation of coagonist action.

\section{Discussion}

We have observed that coagonist of GLP-1R and GCGR decreases hyperlipidemia and FGF21 signalling is required for this action. Our results indicate that coagonist of GLP-1R and GCGR increases FGF21 sensitivity in liver and adipose tissue, which contributes to decrease in dyslipidemia and obesity. We have also observed that FGF21 action is required for the hepatic metabolism of lipids, but not for biliary excretion of cholesterol. In our earlier work [14], we have observed that FGF21 levels were increased after repeated dose treatment of coagonist in diet-induced obese mice. However, it was not known whether this increase can be correlated with the therapeutic benefit. To confirm this, we subjected the hyperlipidemic hamsters to the coagonist treatment, in which the antagonists of GLP$1 R, G C G R$ and FGF21R were co-administered in separate groups.

We observed a partial reversal in antiobesity effect of coagonist by antagonizing either GCGR or GLP-1R action, indicating a combined role of both these hormones in body weight reduction. It is reported that GCGR and GLP-1R agonist treatment reduces food intake [5, 23]. Glucagon is known for its lipolytic effect, while role of GLP-1 in regulating lipolysis is not clear [24, 25]. After repeated treatment of coagonist, we observed increased basal and L-noradrenaline-mediated lipolysis. The lipolytic effect was partially mediated by GLP-1R while almost complete neutralization of lipo- 


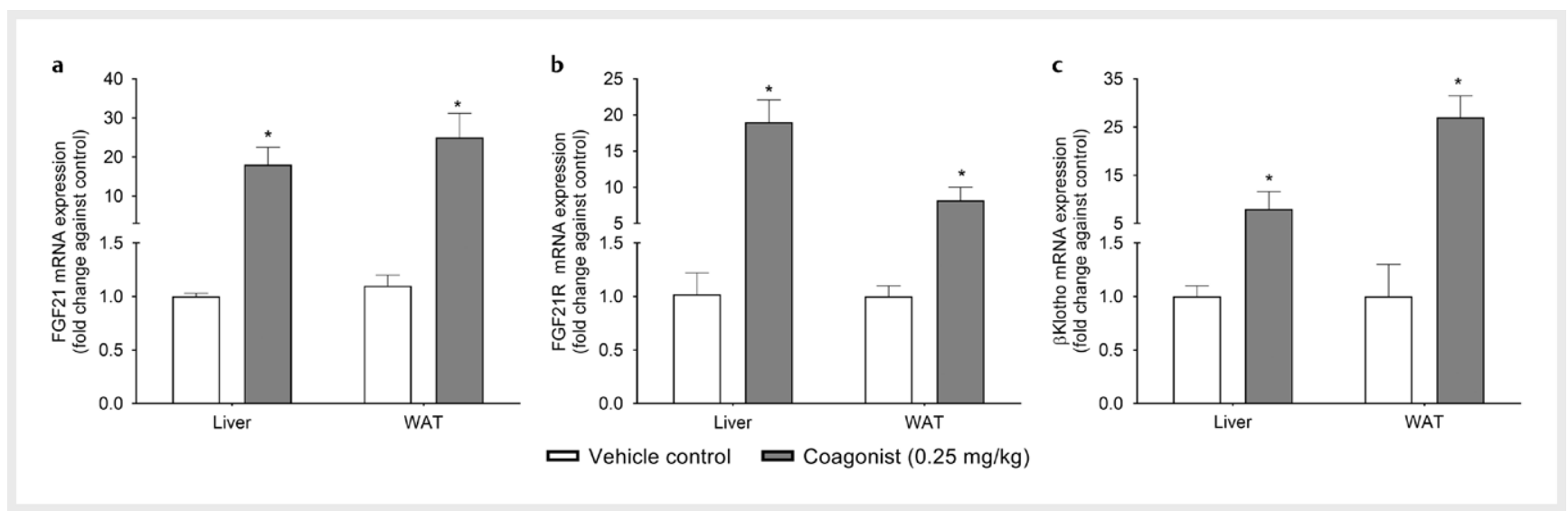

Fig. 4 Effect of chronic treatment of coagonist on mRNA expression levels of a. FGF21, b. FGF21R, c. $\beta K$ lotho, in liver and white adipose tissue of hyperlipidemic hamsters. Data were normalized against vehicle control. Results represent mean $\pm S E M(n=6)$. ${ }^{*} P<0.05$, when compared with vehicle control.

lytic effect was observed after GCGR blockade. Thus, lipolytic effect of the coagonist seems to be primarily mediated by glucagon signalling.

Liver is a major regulator of lipid metabolism in the body. We and others have reported that GLP-1 controls hepatic lipid metabolism $[8,12]$. GLP-1 reduces lipogenesis by activating CAMP-activated protein kinase (AMPK, a suppressor of lipogenesis) and enhancing $\beta$-oxidation by increased expression of peroxisome proliferator-activated receptor alpha, stearoyl-CoA desaturase, SREBP-1C and acetyl-CoA carboxylase [8]. We have observed in our previous studies that GLP-1 reduces SREBP-1c, while increases $L D L R$ and CYP7A1 indicating enhanced removal of lipids from circulation and increases bile salt formation [12]. On the other hand, glucagon suppresses HMG-CoA reductase, thereby suppressing cholesterol synthesis in liver [13]. It also enhances removal of cholesterol in bile. Biliary cholesterol excretion is an important alternative pathway for removal of accumulated lipids in liver. We observed that chronic coagonist treatment reduced plasma triglycerides, plasma cholesterol, plasma LDL and hepatic triglycerides. GLP-1R is mainly involved in triglyceride lowering, while cholesterol and LDL lowering involves GCGR action. GCGR antagonists are being investigated as the therapeutic option for treatment of hyperglycemia. However, it was demonstrated that optimum efficacy of GCGR antagonist requires GLP-1 signalling and that the GLP-1 analog has more favorable impact on lipid and energy metabolism than the GCGR antagonist [4]. On the other hand, chronic glucagon receptor antagonism associated with glucose-lowering demonstrated increase in hepatic fat and hepatic enzyme levels [26]. Hence, a combination of GCGR and GLP-1R agonism can achieve optimum therapeutic efficacy in treatment of dyslipidemia.

We found that coagonist suppresses hepatic triglyceride secretion, partially involving GLP-1 and glucagon receptors. We and others have reported that GLP-1 and glucagon reduce hepatic VLDL secretion [14,27]. We observed that coagonist also increased bile flow rate and biliary cholesterol excretion. GLP-1R blockade attenuated the effect of coagonist on bile flow. On the other hand, GCGR blockade minimized the effect of coagonist on biliary cholesterol excretion. It appears that increase in bile flow is GLP-1R- dependent and cholesterol excretion is dependent on GCGR action.

Glucagon controls glucose, energy, and lipid metabolism in part via FGF21-dependent pathways [28]. We have previously observed that exendin-4 treatment increases FGF21 levels [12]. It is also reported that exendin-4 treatment decreases FGF21 resistance [29]. FGF21 is an endocrine hormone involved in metabolic regulation. It can improve insulin sensitivity and correct dyslipidemia in primates and humans [30]. We have previously observed that coagonist increases FGF21 levels in diet-induced obese mice after repeated dose treatment [14]. In the current work, we have observed that when FGF21R blockade attenuated the effect of GLP-1R/GCGR coagonist on hepatic triglyceride secretion, plasma lipids and hepatic lipids.

FGF21 acts through a receptor complex consisting of a coreceptor, $\beta$ Klotho, and FGF21R located on the cell surface. The pronounced weight loss and improvement in lipid metabolism by coagonist treatment were associated with increase in FGF21 mRNA levels in liver and epididymal white adipose tissue. Circulating levels of FGF21 are elevated in obese diabetic subjects, suggesting FGF21 resistance [31]. However, FGF21 resistance was not evident at the whole-organism level in animal models of genetic or acquired obesity and insulin resistance [32]. Since FGF21R antagonist significantly reduced the metabolic actions of exogenous FGF21, it appears that the FGF21 signalling is intact in dyslipidemic hamsters $[32,33]$. We have observed that coactivation of GLP-1 and GCGR induces FGF21 gene expression and secretion from liver. It is also possible that bile acid flux in the enterohepatic system mediates the increase in FGF21 expression and secretion [33]. The observation that coagonist increased hepatic FGF21 expression as well as FGF21 concentration in the circulation indicates that it is a direct effect of the coagonist as well as an indirect effect of increased bile flow due to the phenotypic changes.

In summary, GLP-1R/GCGR coagonism improves lipids and the associated metabolic syndrome in cholesterol-fed hamsters. The hypolipidemic action of the coagonist requires FGF21 signalling in liver and adipose tissue. 


\section{Acknowledgement}

The authors are grateful to Mr. Pankaj R. Patel, Chairman \& Managing Director, Zydus Cadila, for his encouraging advice and support. ZRC communication no. 472.

\section{Conflict of Interest}

The authors declare that there is no conflict of interest that would prejudice the impartiality of the research reported herein.

\section{References}

[1] Verges B. Pathophysiology of diabetic dyslipidaemia: where are we? Diabetologia 2015; 58: 886-899

[2] Sparks JD, Sparks CE, Adeli K. Selective hepatic insulin resistance, VLDL overproduction, and hypertriglyceridemia. Arterioscler Thromb Vasc Biol 2012; 32: 2104-2112

[3] Day JW, Gelfanov V, Smiley D et al. Optimization of co-agonism at GLP-1 and glucagon receptors to safely maximize weight reduction in DIO-rodents. Biopolymers 2012; 98: 443-450

[4] Gu W, Lloyd D], Chinookswong $N$ et al. Pharmacological targeting of glucagon and glucagon-like peptide 1 receptors has different effects on energy state and glucose homeostasis in diet-induced obese mice. J Pharmacol Exp Ther 2011; 338: 70-81

[5] Drucker D]. Minireview: the glucagon-like peptides. Endocrinology 2001; 142: 521-527

[6] Day JW, Ottaway N, Patterson JT et al. A new glucagon and GLP-1 co-agonist eliminates obesity in rodents. Nat Chem Biol 2009; 5 : 749-757

[7] Cohen MA, Ellis SM, Le Roux CW et al. Oxyntomodulin suppresses appetite and reduces food intake in humans. J Clin Endocrinol Metab 2003; 88: 4696-4701

[8] Ding X, Saxena NK, Lin S et al. Exendin-4, a glucagon-like protein-1 (GLP-1) receptor agonist, reverses hepatic steatosis in ob/ob mice. Hepatology 2006; 43: 173-181

[9] Parlevliet ET, Wang Y, Geerling JJ et al. GLP-1 Receptor activation inhibits vldl production and reverses hepatic steatosis by decreasing hepatic lipogenesis in high-fat-fed APOE * 3-leiden mice. PLoS One 2012; 7: e49152

[10] Caren R, Corbo L. Glucagon and cholesterol metabolism. Metabolism 1960; 9: 938-945

[11] Habegger KM, Heppner KM, Geary N et al. The metabolic actions of glucagon revisited. Nat Rev Endocrinol 201; 6: 689-697

[12] Patel V, Joharapurkar AA, Kshirsagar SG et al. Central GLP-1 receptor activation improves cholesterol metabolism partially independent of its effect on food intake. Can J Physiol Pharmacol. 2016; 94: 161-167

[13] Patel V, Joharapurkar A, Kshirsagar S et al. Central and peripheral glucagon reduces hyperlipidemia in rats and hamsters. Drug Res (Stuttg) 2017; 67: 318-326

[14] Patel V, Joharapurkar A, Dhanesha $\mathrm{N}$ et al. Co-agonist of glucagon and GLP-1 reduces cholesterol and improves insulin sensitivity independent of its effect on appetite and body weight in diet-induced obese C57 mice. Can J Physiol Pharmacol 2013; 91: 1009-1015

[15] Green BD, Mooney MH, Gault VA et al. Lys9 for Glu9 substitution in glucagon-like peptide-1(7-36)amide confers dipeptidylpeptidase IV resistance with cellular and metabolic actions similar to those of established antagonists glucagon-like peptide-1(9-36)amide and exendin (9-39). Metabolism 2004; 53: 252-259
[16] Unson CG, Andreu D, Gurzenda EM et al. Synthetic peptide antagonists of glucagon. Proceedings of the National Academy of Sciences 1987; 84: 4083-4087

[17] Micanovic R, Raches DW, Dunbar JD et al. Different roles of $\mathrm{N}$-and C-termini in the functional activity of FGF21. Journal of Cellular Physiology 2009; 219: 227-234

[18] Dallas-Yang Q, Shen X, Strowski M et al. Hepatic glucagon receptor binding and glucose-lowering in vivo by peptidyl and non-peptidyl glucagon receptor antagonists. Eur J Pharmacol 2004; 501: 225-334

[19] Adams AC, Coskun T, Rovira AR et al. Fundamentals of FGF19 \& FGF21 action in vitro and in vivo. PLoS One 2012; 7: e38438

[20] Patel V, Joharapurkar A, Dhanesha N et al. Combination of omeprazole with GLP-1 agonist therapy improves insulin sensitivity and antioxidant activity in liver in type 1 diabetic mice. Pharmacol Rep 2013; 65: 927-936

[21] Johansson SM, Yang JN, Lindgren E et al. Eliminating the antilipolytic adenosine $\mathrm{A} 1$ receptor does not lead to compensatory changes in the antilipolytic actions of PGE2 and nicotinic acid. Acta Physiol (Oxf) 2007; 190: 87-96

[22] Pocai A, Carrington PE, Adams JR et al. Glucagon-like peptide 1/ glucagon receptor dual agonism reverses obesity in mice. Diabetes 2009; 58: 2258-2266

[23] Quinones M, Al-Massadi O, Gallego R et al. Hypothalamic CaMKKbeta mediates glucagon anorectic effect and its diet-induced resistance. Mol Metab 2015; 4: 961-970

[24] Perea A, Clemente F, Martinell J et al. Physiological effect of glucagon in human isolated adipocytes. Horm Metab Res 1995; 27: 372-375

[25] Villanueva-Penacarrillo ML, Marquez L, Gonzalez N et al. Effect of GLP-1 on lipid metabolism in human adipocytes. Horm Metab Res 2001; 33: 73-77

[26] Guzman CB, Zhang XM, Liu R et al. Treatment with LY2409021, a glucagon receptor antagonist, increases liver fat in patients with type 2 diabetes. Diabetes, Obesity and Metabolism 2017 [Epub ahead of print]

[27] Parlevliet ET, Schroder-van der Elst JP, Corssmit EP et al. CNTO736, a novel glucagon-like peptide-1 receptor agonist, ameliorates insulin resistance and inhibits very low-density lipoprotein production in high-fat-fed mice. J Pharmacol Exp Ther 2009; 328: 240-248

[28] Habegger KM, Stemmer K, Cheng C et al. Fibroblast growth factor 21 mediates specific glucagon actions. Diabetes 2013; 62: 1453-1463

[29] Samson SL, Sathyanarayana P, Jogi M et al. Exenatide decreases hepatic fibroblast growth factor 21 resistance in non-alcoholic fatty liver disease in a mouse model of obesity and in a randomised controlled trial. Diabetologia 2011; 54: 3093-3100

[30] Badman MK, Pissios P, Kennedy AR et al. Hepatic fibroblast growth factor 21 is regulated by PPARalpha and is a key mediator of hepatic lipid metabolism in ketotic states. Cell Metab 2007; 5: 426-437

[31] Fisher FM, Chui PC, Antonellis PJ et al. Obesity is a fibroblast growth factor 21 (FGF21)-resistant state. Diabetes 2010; 59: 2781-2789

[32] Hale C, Chen MM, Stanislaus S et al. Lack of overt FGF21 resistance in two mouse models of obesity and insulin resistance. Endocrinology 2012; 153: 69-80

[33] Cyphert HA, Ge X, Kohan AB et al. Activation of the farnesoid X receptor induces hepatic expression and secretion of fibroblast growth factor 21. J Biol Chem 2012; 287: 25123-25138 